\title{
Article \\ 3D Printed Skin-Wash Sampler for Sweat Sampling in Cystic Fibrosis Diagnosis Using Capillary Electrophoretic Ion Ratio Analysis
}

\author{
Miriam Malá ${ }^{1,2}$, Petra Itterheimová ${ }^{3,4}$, Lukáš Homola ${ }^{1,2}$, Jana Vinohradská 5,6 ${ }^{\mathbb{D}}$ and Petr Kubán̆ an $^{4}, * \mathbb{D}$ \\ 1 Department of Pediatric Infectious Diseases, Centre of Cystic Fibrosis, University Hospital Brno, \\ 66263 Brno, Czech Republic; mala.miriam@fnbrno.cz (M.M.); homola.lukas@fnbrno.cz (L.H.) \\ 2 Faculty of Medicine, Masaryk University, 62500 Brno, Czech Republic \\ 3 Central European Institute of Technology, Faculty of Science, Masaryk University, \\ 62500 Brno, Czech Republic; p.itterheimova@gmail.com \\ 4 Department of Bioanalytical Instrumentation, Institute of Analytical Chemistry, Czech Academy of Sciences, \\ 60200 Brno, Czech Republic \\ 5 Centre of Molecular Biology and Genetics, Department of Internal Medicine-Hematology and Oncology, \\ University Hospital Brno, Faculty of Medicine, Masaryk University, 62500 Brno, Czech Republic; \\ Vinohradska.Jana@fnbrno.cz \\ 6 Department of Experimental Biology, Faculty of Science, Masaryk University, 61137 Brno, Czech Republic \\ 7 Department of Chemistry, Faculty of Science, Masaryk University, Kotlářská 2, 61137 Brno, Czech Republic \\ * Correspondence: petr.kuban@iach.cz; Tel.: +420-532290142
}

check for updates

Citation: Malá, M.; Itterheimová, P.; Homola, L.; Vinohradská, J.; Kubáň, P. 3D Printed Skin-Wash Sampler for Sweat Sampling in Cystic Fibrosis Diagnosis Using Capillary Electrophoretic Ion Ratio Analysis. Separations 2021, 8, 234. https:// doi.org/10.3390/separations8120234

Academic Editor: Pavel Nikolaevich Nesterenko

Received: 10 November 2021 Accepted: 30 November 2021 Published: 3 December 2021

Publisher's Note: MDPI stays neutral with regard to jurisdictional claims in published maps and institutional affiliations.

Copyright: (c) 2021 by the authors. Licensee MDPI, Basel, Switzerland. This article is an open access article distributed under the terms and conditions of the Creative Commons Attribution (CC BY) license (https:/ / creativecommons.org/licenses/by/ $4.0 /)$.

\begin{abstract}
Sweat chloride analysis is one of the important approaches in cystic fibrosis diagnosis. The commonly used Macroduct method to acquire sweat samples is semi-invasive, time consuming and expensive. Furthermore, this method often fails to collect a sufficient amount of sweat in newborns due to the insufficient sweating rate. In this work, we present a novel, simple, 3D-printed sampling device that is used to collect sweat specimens completely noninvasively in less than one minute. The device has a flow-through channel adjacent to the skin surface, through which $500 \mu \mathrm{L}$ of deionized water is flushed and the spontaneously formed sweat on the skin in the channel area is washed into a plastic vial. The developed skin-wash procedure is a single step operation, is completely noninvasive and it always produces a sweat specimen. The ions from the skin-wash are subsequently analyzed by capillary electrophoresis with contactless conductivity detection and selected ion ratio $\left(\mathrm{Cl}^{-} / \mathrm{K}^{+}\right)$or $\left(\left(\mathrm{Cl}^{-}+\mathrm{Na}^{+}\right) / \mathrm{K}^{+}\right)$is used as a cut-off value to diagnose cystic fibrosis patients with sensitivity and specificity comparable to the conventional Macroduct method.
\end{abstract}

Keywords: cystic fibrosis; sweat sampling; skin-wash; capillary electrophoresis; contactless conductivity detection; ion ratio

\section{Introduction}

Sweat is an important diagnostic sample in cystic fibrosis (CF), a rare incurable autosomal recessive inherited disease [1]. The mutation in cystic fibrosis transmembrane conductance regulator (CFTR) gene results in defective ion transfer through epithelial cellular membranes in CF patients and the unambiguous diagnostic tool is to measure the chloride concentration in sweat. The value above $60 \mathrm{mmol} / \mathrm{L}$ [2] is used as a cut-off to confirm the diagnosis of $\mathrm{CF}$ diagnosis in newborn screening programs across the world [3]. However, a clearly negative result of the sweat test is a value below $30 \mathrm{mmol} / \mathrm{L}$, and the gray zone of the range between these values should be interpreted in connection with the clinical condition of the patient and possibly after the completion of other tests, including genetic testing.

Currently, pilocarpine iontophoresis sweat induction is considered the golden standard for acquiring a sweat sample [4], and one of the widely used methods is a Macroduct 
sweat sampling method. A pilocarpine disc (Pilogel) is placed on the patient's forearm and an electric current is applied to introduce pilocarpine under the skin and induce sweat production in the sweat glands. Not only is Macroduct sweat sampling time-consuming and partly invasive, but it has also recently become relatively costly. According to a recent report, in more than $37 \%$ of CF centers, the cost of Macroduct sampling exceeded the reimbursement paid by medical insurance companies [5]. Additionally the Macroduct sampling method sometimes does not produce the sufficient amount of sweat required for further analysis, especially in infants, as their sweat rates are low [5]. This requires multiple visits to the CF center and repeated testing. There are alternative methods in addition to the Macroduct sweat sampling. For example, it was suggested to measure sweat conductivity [6,7] or to use sodium cation instead of chloride [8,9]. Recently, wearable devices for on-line monitoring of sweat chloride were presented [10-12]. However, in all these methods, sweat induction by pilocarpine is required.

Simplified diagnostic methods, preferably without the tedious sweat induction, but with comparable performance, would be highly advantageous.

Recently, we have developed an alternative, simple method for sweat sampling that we labelled "skin-wipe" [13-15]. This method utilized a cotton swab moistened with deionized (DI) water with which the spontaneously formed sweat from the forearm was wiped, the ions from the cotton swab were subsequently extracted by immersion in DI water and analyzed by capillary electrophoresis. Since a European Union (EU) directive effective as of 2019 [16] bans the use of cotton swabs with plastic parts in the EU, this previously presented method became difficult to practice. Replacement with nonplastic cotton swabs proved to be unsuitable for sweat collection purposes, due to the high contamination of the new material and the difficulty in their cleaning. Additionally, the whole cleaning procedure is time-consuming.

In this contribution, we have developed a new, alternative method to obtain the spontaneously formed sweat sample, which we label the "skin-wash". For "skin-wash", novel sampling devices were designed and 3D-printed using an LCD-based SLA 3D printer (Hongkong Anycubic Technology, 45-54 Chatham Road South, Kowloon, Hong Kong). The sampling device is placed on the forearm of the subject and $500 \mu \mathrm{L}$ of DI water is flushed through its chamber, adjacent to the forearm skin. The sweat formed on the skin under a defined channel area is "washed" with DI water in one simple step and the sweat sample, albeit diluted, is ready for analysis. Capillary electrophoresis with contactless conductometric detection is a suitable technique to analyze all ions (anions and cations) in these samples [13-15,17] and by using the diagnostic parameter previously developed, i.e., the ion ratio $\left(\mathrm{Cl}^{-} / \mathrm{K}^{+}\right)$or $\left(\left(\mathrm{Cl}^{-}+\mathrm{Na}^{+}\right) / \mathrm{K}^{+}\right)$as a cut-off value, a comparable performance to the conventional Macroduct test with coulometric chloride analysis is obtained. The presented "skin-wash" method, however, presents a completely non-invasive, simple, and faster alternative that has the potential to become a new diagnostic or screening approach for CF.

\section{Materials and Methods}

\subsection{Chemicals and Standards}

The stock solutions of inorganic anions and cations were prepared from ACS grade sodium and chloride salts $\left(\mathrm{NaCl}, \mathrm{NaNO}_{3}, \mathrm{NaNO}_{2}, \mathrm{Na}_{2} \mathrm{SO}_{4}, \mathrm{KCl}, \mathrm{CaCl}_{2}, \mathrm{MgCl}\right.$ ). Ammonium cation stock solution was prepared from $\mathrm{NH}_{4} \mathrm{~F}$. All inorganic salts were obtained from Pliva-Lachema, Brno, Czech Republic. DI water (Purite, Neptune, Watrex, Prague, Czech Republic) was used for all stock solutions preparation. The calibration solutions were prepared by diluting the stock solutions with DI water to the required concentration. Stock solutions for background electrolyte (BGE) were prepared from 2-(N-morpholino) ethanesulfonic acid (MES, $200 \mathrm{mmol} / \mathrm{L})$, L-histidine (His, $200 \mathrm{mmol} / \mathrm{L}$ ), 18-Crown-6 (100 mmol/L) and cetyltrimethylammonium bromide (CTAB, $10 \mathrm{mmol} / \mathrm{L})$. All were from Sigma-Aldrich, Steinheim, Germany. The final concentration in the BGE was 
$20 \mathrm{mmol} / \mathrm{L}$ for MES and His, $2 \mathrm{mmol} / \mathrm{L}$ for 18 -crown- 6 and $30 \mu \mathrm{M}$ for CTAB. The $\mathrm{pH}$ of the BGE was 6.

\subsection{Capillary Electrophoresis System}

Fused silica capillaries (Microquartz GmbH, Munich, Germany) were used for ion separation. A new capillary was first preconditioned with $0.1 \mathrm{~mol} / \mathrm{L} \mathrm{NaOH}$ for $30 \mathrm{~min}$, followed by a 30-min wash with DI water and finally a 30-min wash with the BGE. Between the analyses, the capillary was flushed with the BGE for $100 \mathrm{~s}$. At the end of the working day, the separation capillary was washed with DI water for $15 \mathrm{~min}$, vacuum dried and stored dry overnight.

All samples were analyzed using an Agilent 7100 Capillary Electrophoresis (CE) System (Agilent Technologies, Santa Clara, CA, USA) with a contactless conductivity detector (C4D), (Ver. 5.06, ADMET, Prague, Czech Republic). The separation voltage was $-15 \mathrm{kV}$ for anions and $+15 \mathrm{kV}$ for cations. The separation capillary had an inner diameter of $50 \mu \mathrm{m}$ and the outer diameter of $375 \mu \mathrm{m}$. The capillary was $40 \mathrm{~cm}$ long, with the detector placed at the distance of $31.5 \mathrm{~cm}$ from the injection side. Samples were injected hydrodynamically at 50 mbar for $5 \mathrm{~s}$. Each sample was analyzed in triplicate and the data are expressed as means.

\subsection{D-Printed Sampling Device Fabrication}

A 3D model of the sampling device was designed in the free version of SketchUp software. The schematic of the device is provided in the Supplementary Material, Figure S1. The final STL file (Supplementary Materials) was processed by Anycubic Photon Slicer V1.3.3 using the following parameters: Layer thickness $-0.05 \mathrm{~mm}$; Normal exposure time$15 \mathrm{~s}$; Off time $-1 \mathrm{~s}$; Bottom exposure time $-120 \mathrm{~s}$ and bottom layers -3 . The acquired processed file was then transferred to the Anycubic Photon 3D printer (Hongkong Anycubic Technology, 45-54 Chatham Road South, Kowloon, Hong Kong). The devices were printed from a clear UV-sensitive resin (Shenzhen Anycubic Technology, Co. LTD., Shenzhen, China). The sampling devices were reused after being soaked overnight in a beaker with DI water and flushed under a stream of DI water for one minute and dried with air. There was no significant contamination with inorganic ions after this cleaning procedure, as verified by blank CE analysis.

\subsection{Sampling}

\subsubsection{Skin-Wipe Samples}

To obtain skin-wipe samples, the skin of the forearm was cleaned with a non-sterile gauze (Sterilux.ES, Hartmann-Rico, Veverská Bitýška, Czech Republic) soaked in medical grade denatured ethanol, followed by wiping with gauze soaked in DI water and then dried with a dry gauze. Spontaneous sweat formation was then allowed for $5 \mathrm{~min}$. A cotton swab wetted with $100 \mu \mathrm{L}$ of DI water was used for repeated wiping $(10 \times)$ of a defined area of skin (approximately $10 \mathrm{~cm}^{2}$ ). The cotton swab was then immersed in $400 \mu \mathrm{L}$ of DI water and allowed to stand for $3 \mathrm{~min}$ to extract the analytes. The swab was then discarded, and the extract was stored at $-80^{\circ} \mathrm{C}$. Cotton swabs used for the skin-wipe procedure had been cleaned prior to use, the cleaning procedure has been previously published [15].

\subsubsection{Skin-Wash Samples}

Skin-wash samples were obtained at the same time as the skin-wipe samples, following the same cleaning procedure as described above. After the same wait time period of $5 \mathrm{~min}$, a skin-wash device was placed on the forearm with the wash channel facing down. A syringe with $500 \mu \mathrm{L}$ of DI water and an air pocket $(2.5 \mathrm{~mL})$ above the liquid was slowly depressed, so that the DI water would flow through the channel. The complete procedure is shown schematically in Figure 1 . The $500 \mu \mathrm{L}$ volume of water pushed through the channel washed all the sweat formed in the area of the channel and was transferred to a plastic vial. The air pocket in the syringe served to remove all the water remaining in the channel 
so that the transfer was nearly quantitative. The sample vial was stored at $-80^{\circ} \mathrm{C}$ when not analyzed immediately. Figure 2 shows the photograph of the disassembled 3D printed sampling device, placed upside down with the channel clearly visible on the top. The channel has a specific shape (see Figure S1 in the Supplementary Material) that makes the DI water flow through the device easily. Figure 2 also shows a photograph of the assembled device with all parts (a $5 \mathrm{~mL}$ syringe, a Teflon tubing, a $1.5 \mathrm{~mL}$ Eppendorf Safe-Lock Tube and a rubber band) and its position during sampling. The whole sampling procedure took about $1 \mathrm{~min}$ (excluding the 5-min waiting period for spontaneous sweat formation).

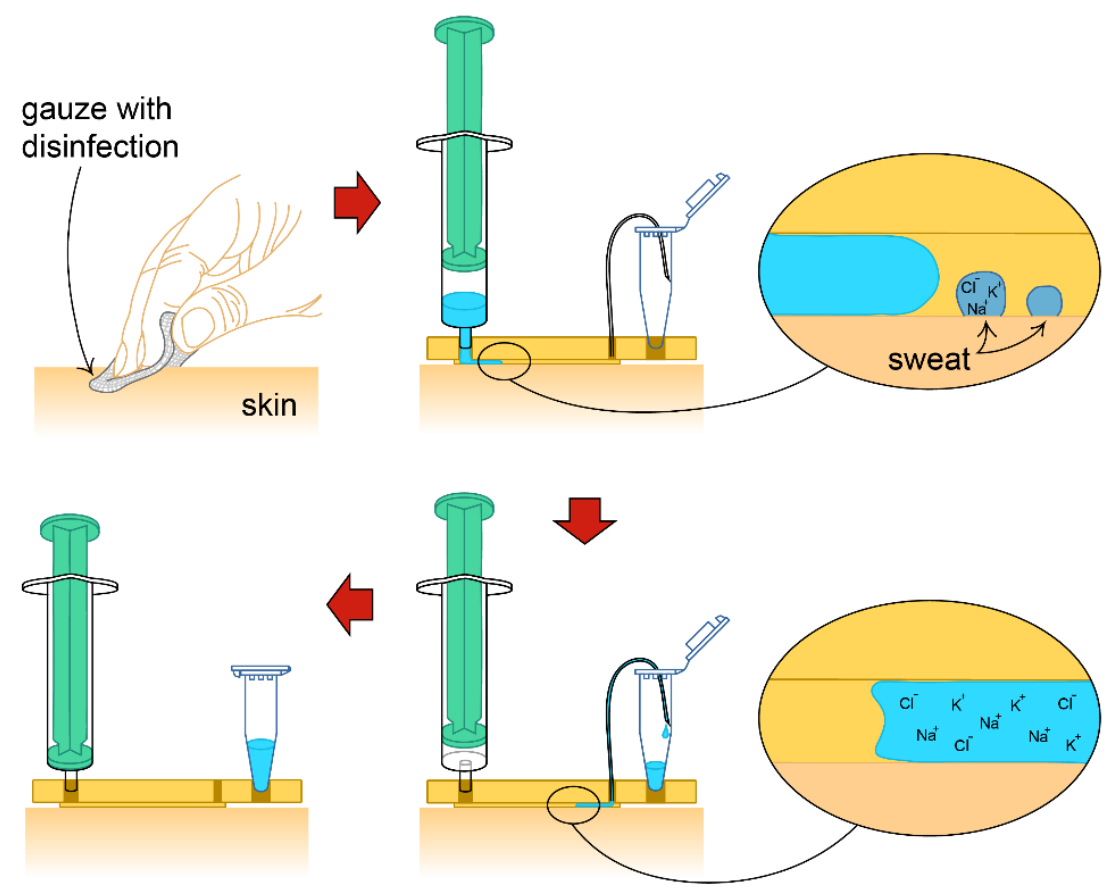

Figure 1. A schematic of the "skin-wash" procedure.
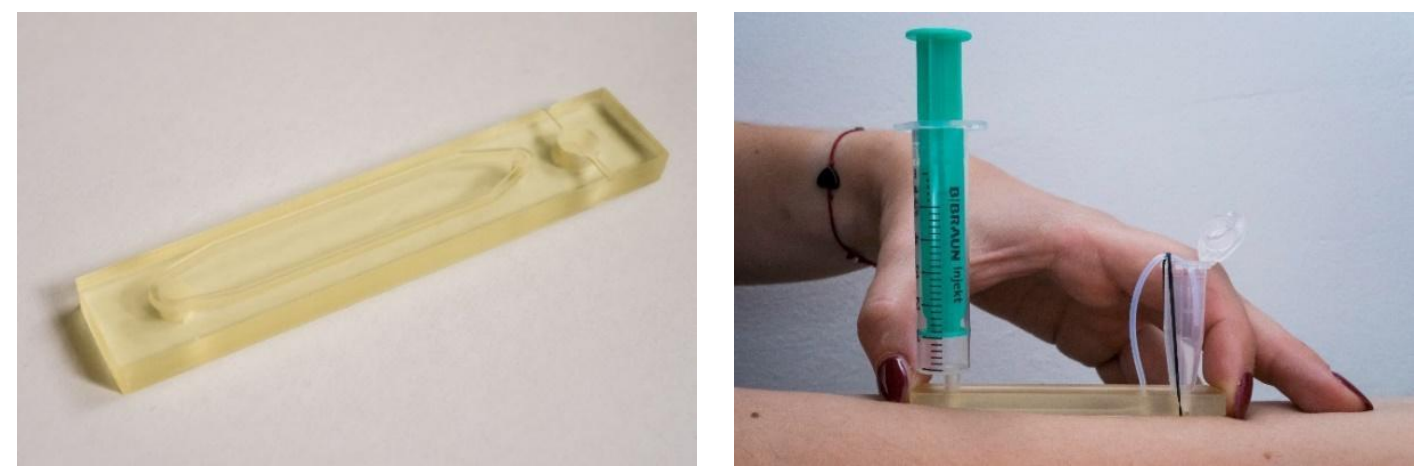

Figure 2. A photograph of the 3D printed sampling device (upside down) and a photograph of the fully assembled device with the syringe and the collection vial, placed on the subject's forearm, ready for sampling.

\subsubsection{Macroduct Sampling}

Conventional sweat samples were acquired using the Macroduct ${ }^{\circledR}$ Sweat Collection System, Model 3700-SYS (Elitech, Puteaux, France) [4]. Sweat was formed after stimulation with pilocarpine gel discs (Piloge ${ }^{\circledR}$ ) and Webster Model 3700 sweat inducer (Elitech, Puteaux, France). The stimulation procedure took $10 \mathrm{~min}$. The sweat formed was collected by the Macroduct Sweat Collector device for an additional $30 \mathrm{~min}$. All sample collection procedures were performed according to standardized guidelines [18]. Samples were transferred to polypropylene vials and analyzed in the laboratory for chloride using a 
Sherwood Model 926A chloride analyzer (Sherwood Scientific, Cambridge, UK). When not immediately analyzed, the samples were stored at $-80^{\circ} \mathrm{C}$.

\subsection{Study Subjects}

The study protocol was reviewed and approved by the Ethics Committee of the University Hospital Brno (28 August 2014). All participants signed a written informed consent. All samples were blinded during the analyses. The total number of participants was 65:22 patients diagnosed with CF ( 2 to 21 years), 22 healthy carriers ( 2 to 23 years), and 21 healthy control individuals ( 5 to 26 years).

For cohort definition, we used clinical signs of cystic fibrosis confirmed by the CF specialist, presence of CF-causing CFTR mutations confirmed by DNA analysis and the Macroduct sweat test performed at the time of the study. Sweat tests can provide negative (sweat chloride $<30 \mathrm{mmol} / \mathrm{L}$ ), intermediary (sweat chloride 30 to $60 \mathrm{mmol} / \mathrm{L}$ ) or positive results (sweat chloride $>60 \mathrm{mmol} / \mathrm{L}$ ).

The cystic fibrosis cohort was defined as patients with two CF-causing CFTR mutations, an intermediary or positive sweat test and the presence of clinical signs of CF.

The healthy CF carrier cohort was defined as healthy individuals with only one CF-causing CFTR mutation, negative or intermediary sweat test, and no clinical signs of $\mathrm{CF}$.

The healthy control cohort was defined as individuals without the CF-causing CFTR mutation, negative or intermediary sweat test, and no clinical signs of $\mathrm{CF}$.

A detailed description of the patient cohort, with their characterization and details on the DNA analyses and sweat test results are summarized in the Supplementary Materials (Tables S1-S3).

\section{Results and Discussion}

\subsection{Capillary Electrophoretic Analysis of Sweat Samples}

The analysis of the sweat samples was performed on a commercial CE instrument with a C4D. The previously optimized BGE consisting of $20 \mathrm{mmol} / \mathrm{L} \mathrm{His,} 20 \mathrm{mmol} / \mathrm{L}$ MES, $2 \mathrm{mmol} / \mathrm{L} 18$-crown- 6 and $30 \mu \mathrm{mol} / \mathrm{L}$ CTAB at $\mathrm{pH} 6$ was used. CTAB was used to suppress the electroosmotic flow and reduce the analysis time of the anions. The analysis took $3.5 \mathrm{~min}$ for cations and anions, respectively, totaling about 10 min including the injection and washing steps. The same system and BGE were used for analysis of anions and cations, except that the polarity of the high-voltage power supply was switched from positive (cations) to negative (anions). Total analysis time can be significantly reduced by using short capillaries in an in-house built system, as documented in several previous publications [19-21]. Figure 3 shows a typical electropherogram of a skin-wipe and skin-wash sample from a CF patient with both anions and cations separated. The traces of both methods are very similar, proving the suitability of the developed skin-wash method. However, because the absolute amounts of the ions in each sample are different, a specific dilution was used for each sample. Typically, the conductivity of each sample was measured prior to dilution and the dilution was performed according to the measured value to fit within the calibration curve. Calibration was measured for all anions and cations in the range of 0-50 $\mu \mathrm{mol} / \mathrm{L}$ with the analytical parameters shown in Table S4 in the Supplementary Material. All other parameters such as limits of detection, limits of quantitation and repeatability of migration times and peak areas were previously validated [14].

\subsection{Comparison of Skin-Wash and Skin-Wipe Sampling}

In a previous comprehensive study (where skin-wipe sampling was performed in multiple CF centers) a total of 248 samples were analyzed and the receiver operating characteristic curves were plotted [15] to describe the diagnostic ability of the method. The simple ion ratio $\mathrm{Cl}^{-} / \mathrm{K}^{+}$and the extended ion ratio $\left(\left(\mathrm{Cl}^{-}+\mathrm{Na}^{+}\right) / \mathrm{K}^{+}\right)$were used as diagnostic parameters. Previously a cut-off value of 3.9 was selected for skin-wipe samples, when the $\mathrm{Cl}^{-} / \mathrm{K}^{+}$ion ratio was used. Figure 4 shows that in this work all studied subjects 
would be correctly classified using this ion ratio, with $100 \%$ specificity and sensitivity. This is valid for both the skin-wipe and the newly developed skin-wash methods.

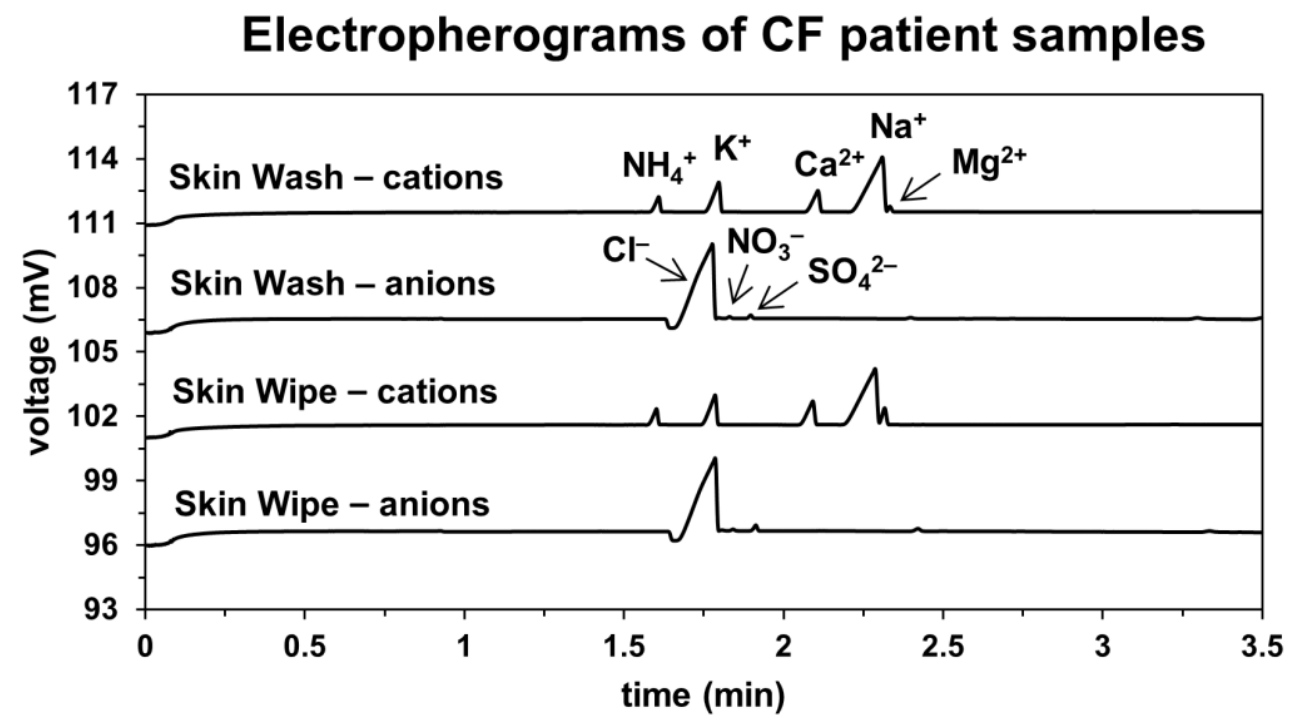

Figure 3. Electropherogram of a CF patient showing anion and cation analysis in skin-wash and skin-wipe samples. CE conditions: $20 \mathrm{mM}$ MES/His, $2 \mathrm{mM}$ 18-crown-6, $30 \mu \mathrm{M}$ CTAB at pH 6 . Injection: $50 \mathrm{mbar} / 5 \mathrm{~s}$, Separation voltage $+15 \mathrm{kV}$ for cations, $-15 \mathrm{kV}$ for anions. Samples were diluted 1:1 with DI water.

Skin Wash: $\mathrm{Cl} / \mathrm{K}$

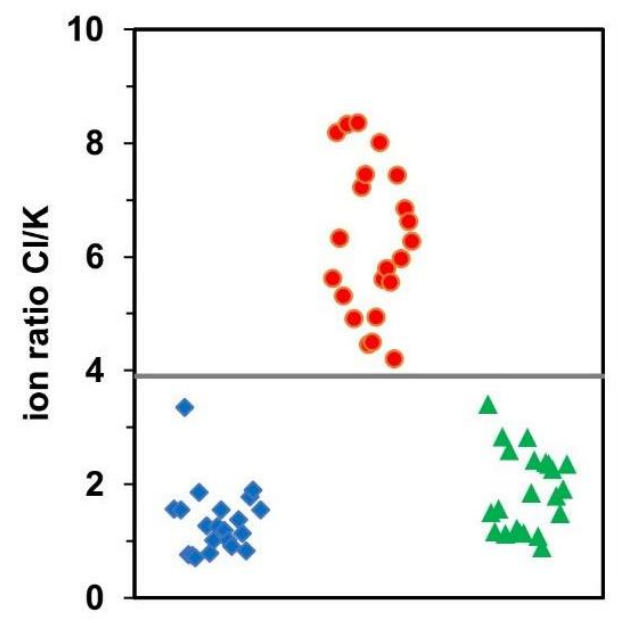

- Healthy controls $\bullet$ CF patients

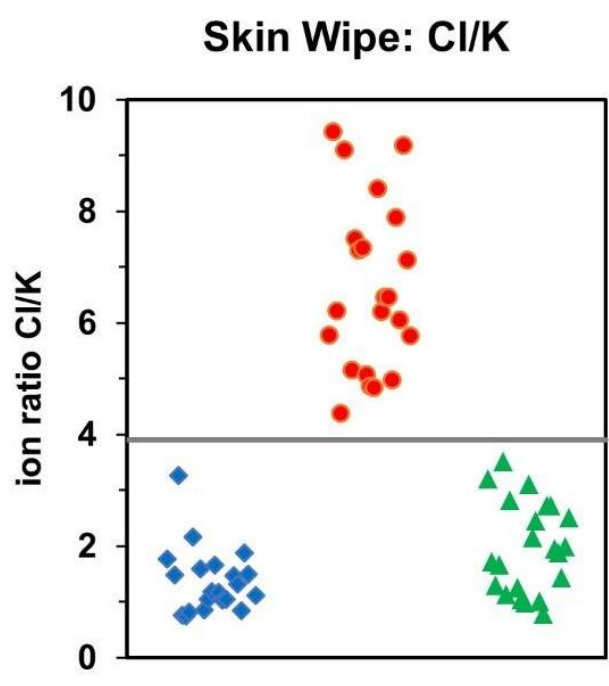

$\Delta$ Healthy carriers Cut-off

Figure 4. Comparison of $\mathrm{Cl}^{-} / \mathrm{K}^{+}$ion ratio from skin-wash and skin-wipe samples. Both datasets were obtained from the same persons, sampling was performed at the same time using both forearms. Each data point is an average of two samples taken from right and left forearm.

The previously calculated cut-off value of 5.0 was then applied for all samples, with the extended ion ratio $\left(\left(\mathrm{Cl}^{-}+\mathrm{Na}^{+}\right) / \mathrm{K}^{+}\right)$. Figure 5 shows that using the new skin-wash method, two studied subjects (one healthy and one CF carrier) would be incorrectly classified, and all CF patients were correctly classified, resulting in $100 \%$ sensitivity and $95.4 \%$ specificity. Using the skin-wipe sampling method, the number of false positives would be higher, especially in the healthy carrier group, demonstrating the advantage of using the new skin-wash sampling method. Although the sensitivity would be $100 \%$ again, the specificity would drop to $88.4 \%$ using skin-wipe sampling. The reason for the superiority of the new skin-wash method might be the lower contamination. We have noticed that although 
cleaned carefully, a small contamination with ions (especially sodium and calcium cations) could be observed in the cotton swabs. The higher contamination with $\mathrm{Na}^{+}$cations might have caused a decrease in the specificity of the skin-wipe method. However, even with the combined ion ratios, all patients with CF were again classified correctly, which is the ultimate goal of any screening method.

Skin Wash: $(\mathrm{Cl}+\mathrm{Na}) / \mathrm{K}$

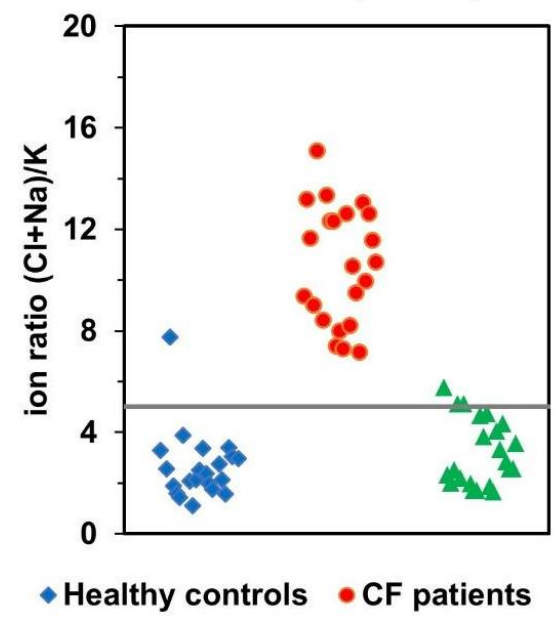

Skin Wipe: $(\mathrm{Cl}+\mathrm{Na}) / \mathrm{K}$

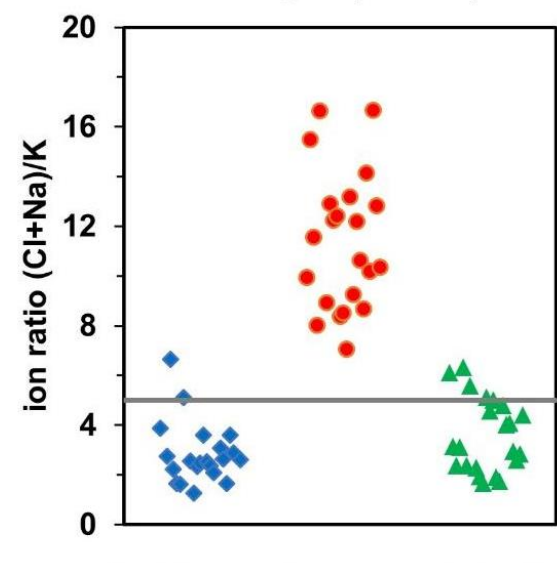

$\Delta$ Healthy carriers $\longrightarrow$ Cut-off

Figure 5. Comparison of $\left(\mathrm{Cl}^{-}+\mathrm{Na}^{+}\right) / \mathrm{K}^{+}$ion ratio from skin-wash and skin-wipe samples. Both datasets were obtained from the same persons, sampling was performed at the same time using both forearms. Each data point is an average of two samples taken from right and left forearm.

\subsection{Correlation of Skin-Wash and Skin-Wipe Samples}

To validate the newly developed skin-wash method, the ion ratios obtained for the skin-wash method and for the skin-wipe method were compared and plotted in a correlation graph. The results of both sampling approaches are shown in Figure 6. The correlation matrix consisted of $\mathrm{Cl}^{-} / \mathrm{K}^{+}$ion ratios (Figure 6, left panel) and of $\left(\left(\mathrm{Cl}^{-}+\mathrm{Na}^{+}\right) / \mathrm{K}^{+}\right)$ion ratios (Figure 6, right panel) from all 65 samples from all study groups, left and right hand samples separately. The uncertainties of the coefficients of the slope and the intercept were calculated and a $t$-value (Student's $t$-test) for the intercept was obtained. The $t$-value was compared to corresponding critical value, and it was found that the intercept is statistically insignificant. The Pearson correlation coefficients $\left(\mathrm{R}=0.9907\right.$ for the $\mathrm{Cl}^{-} / \mathrm{K}^{+}$ion ratio and 0.9928 for the $\left(\left(\mathrm{Cl}^{-}+\mathrm{Na}^{+}\right) / \mathrm{K}^{+}\right)$ion ratio) demonstrate an excellent correlation between the two methods.
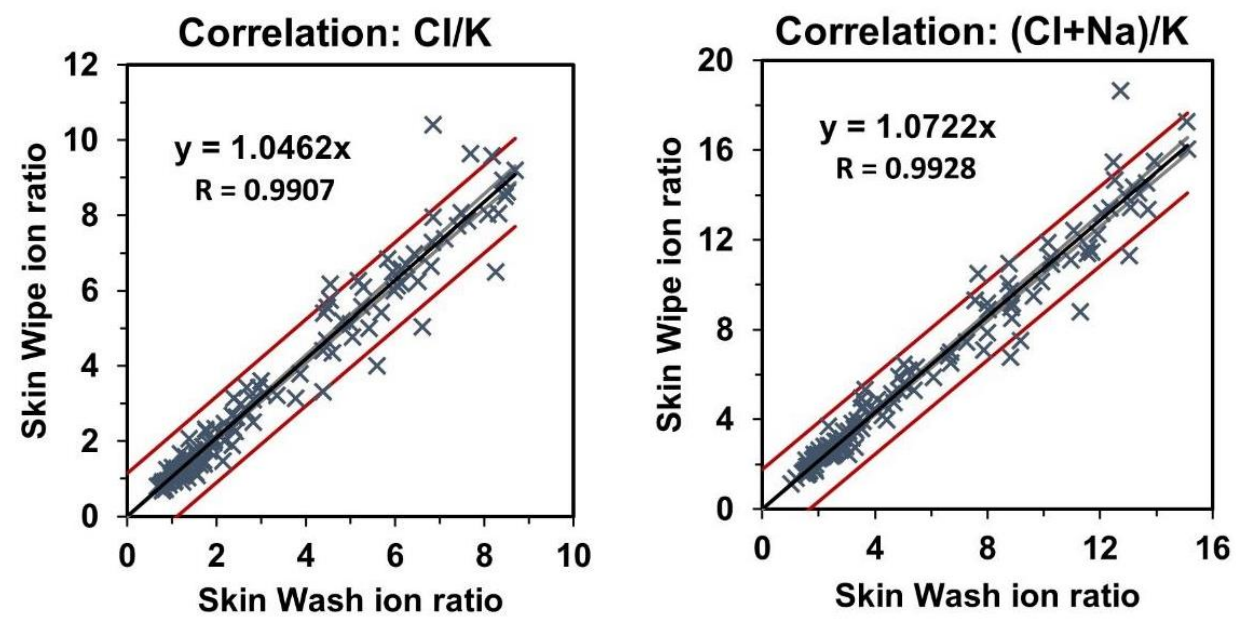

Figure 6. Correlation of data obtained from skin-wash and skin-wipe methods. The black line is the regression line, grey lines define the confidence interval, and red lines define the prediction band. 


\subsection{Analysis of Ion Ratios after Sweat Stimulation with Pilopcarpine}

The skin-wash and skin-wipe methods use spontaneous sweat formation with no induction. This approach is much more friendly to the patient, as no chemicals are applied to the skin. It was of interest to us to test whether the sweat induction by pilocarpine, as used in the conventional Macroduct sampling method, introduces some noticeable changes in the sweat composition compared to the composition of spontaneously formed sweat. For this purpose, the skin of the forearm to which the pilocarpine was applied to obtain the Macroduct sample was subjected to the skin-wipe method right after the Macroduct procedure was finished. We have analyzed all skin-wipe samples "post-Macroduct" and the results are shown in the Supplementary Materials, Figures S2 and S3. It was interesting to note that the absolute values of the ion ratios with sweat induction were significantly higher than those of the spontaneously formed sweat. This invalidates the previous cutoff values, and Figure S2 shows that after the sweat induction, the performance of the method deteriorated significantly. We assume that the sweat induction by pilocarpine alters somewhat the composition of the sweat. Therefore, our skin-wash and skin-wipe methods are only suitable without sweat stimulation, which is actually an apparent advantage of our method. However, the results obtained could stimulate an interest in further research to elucidate the differences in sweat composition with and without stimulation. Figure S3 then shows a rather poor correlation of the ion ratios with and without sweat stimulation, corroborating the conclusions made above.

\section{Conclusions}

In this contribution, we have successfully tested a simplified sampling method for obtaining sweat samples. We denote this method "skin-wash" as it uses a 3D printed skinwash device to obtain a spontaneously formed sweat sample from the patient's forearm. This newly developed procedure is significantly simpler than the previous skin-wipe method. Compared to routine Macroduct sweat sampling and analysis, the skin-wash method is moreover non-invasive and faster. It does not use pilocarpine and electric current on the patient's skin for sweat induction, which is of importance especially in newborn screening. Although the concentrations of ions in skin-wash samples are significantly lower than those in conventional sweat samples, the CE-C4D technique is sufficiently sensitive to analyze all ions in these samples in a very short time. We propose the use of $\mathrm{Cl}^{-} / \mathrm{K}^{+}$ratio of ion concentrations obtained from the skin-wash samples, with a cut-off value of 3.9, as a useful diagnostic tool complementary to the conventional sweat chloride analysis.

Supplementary Materials: The following are available online at https:/ / www.mdpi.com/article / 10.3390 / separations8120234/s1, Figure S1. A schematic of the 3D-printed device. Figure S2. Comparison of $\mathrm{Cl}^{-} / \mathrm{K}^{+}$and $\left(\left(\mathrm{Cl}^{-}+\mathrm{Na}^{+}\right) / \mathrm{K}^{+}\right)$ion ratios from skin-wipe samples after stimulation of sweating by pilocarpine. Both datasets were obtained from the same persons. Figure S3. Correlation of data obtained from skin-wipe sample before and after sweat stimulation with pilocarpine. Table S1: Healthy subjects without CF-causing CFTR mutations. Table S2: CF carriers—subjects with CF-causing CFTR mutation in one allele. Table S3a: Cystic fibrosis female patients-subjects with CF-causing CFTR mutation in two alleles. Table S3b: Cystic fibrosis male patients-subjects with CF-causing CFTR mutation in two alleles. Table S4. Calibration slopes and regression coefficients for chloride, potassium and sodium ions. Correlation of data obtained from skin-wipe sample before and after sweat stimulation with pilocarpine.

Author Contributions: Conceptualization, M.M. and L.H.; methodology, M.M., P.I., L.H. and P.K.; investigation, P.I., M.M. and J.V.; data curation, P.I., M.M. and J.V.; writing-original draft preparation, P.K. and P.I.; writing-review and editing, P.I., M.M., L.H. and P.K.; supervision, P.K. and L.H.; funding acquisition, L.H. and P.K. All authors have read and agreed to the published version of the manuscript.

Funding: This research was funded by the Ministry of Health of the Czech Republic, grant number NV18-08-00189 and by the Czech Academy of Sciences, the institutional support RVO: 68081715. Participating researchers and data contributors participate in the ERN LUNG. 
Institutional Review Board Statement: The study was conducted according to the guidelines of the Declaration of Helsinki, and approved by the Ethics Committee of the University Hospital Brno, Czech Republic (28 August 2014).

Informed Consent Statement: Informed consent was obtained from all subjects involved in the study.

Data Availability Statement: The data presented in this study are available on request from the corresponding author. The data are not publicly available due to the ethical reasons.

Conflicts of Interest: The authors declare no conflict of interest.

\section{References}

1. Le Grys, V.A. Sweat testing for the diagnosis of cystic fibrosis: Practical considerations. J. Pediatr. 1996, 129, 892-897. [CrossRef]

2. Farrell, P.M.; Rosenstein, B.J.; White, T.B.; Accurso, F.J.; Castellani, C.; Cutting, G.R.; Durie, P.R.; LeGrys, V.A.; Massie, J.; Parad, R.B.; et al. Guidelines for diagnosis of cystic fibrosis in newborns through older adults: Cystic fibrosis foundation consensus report. J. Pediatr. 2008, 153, 4-14. [CrossRef] [PubMed]

3. Castellani, C.; Massie, J.; Sontag, M.; Southern, K.W. Newborn screening for cystic fibrosis. Lancet Respir. Med. $2016,4,653-661$. [CrossRef]

4. Elitech Group. Macroduct Sweat Collection System. Available online: https://www.elitechgroup.com/products/sweat-testing/ sweat-collection (accessed on 29 November 2021).

5. Cirilli, N.; Southern, K.W.; Buzzetti, R.; Barben, J.; Nährlich, L.; Munck, A.; Wilschanski, M.; De Boeck, K.; Derichs, N.; ECFS Diagnostic Network Working Group. Real life practice of sweat testing in Europe. J. Cyst. Fibros. 2018, 17, 325-332. [CrossRef] [PubMed]

6. Lezana, J.L.; Vargas, M.H.; Karam-Bechara, J.; Aldana, R.S.; Furuya, M.E. Sweat conductivity and chloride titration for cystic fibrosis diagnosis in 3834 subjects. J. Cyst. Fibros. 2003, 2, 1-7. [CrossRef]

7. Vernooij-van Langen, A.; Dompeling, E.; Yntema, J.B.; Arets, B.; Tiddens, H.; Loeber, G.; Dankert-Roelse, J. Clinical evaluation of the Nanoduct sweat test system in the diagnosis of cystic fibrosis after newborn screening. Eur. J. Pediatr. 2015, 174, 1025-1034. [CrossRef] [PubMed]

8. Mishra, A.; Greaves, R.; Massie, J. The limitation of sweat electrolyte reference intervals for the diagnosis of cystic fibrosis: A systemic review. Clin. Biochem. Rev. 2007, 28, 60-66. [PubMed]

9. Traeger, N.; Shi, Q.; Dozor, A.J. Relationship between sweat chloride, sodium and age in clinically obtained samples. J. Cyst. Fibros. 2014, 13, 10-14. [CrossRef] [PubMed]

10. Choi, D.H.; Kim, J.S.; Cutting, G.R.; Searson, P.C. Wearable potentiometric chloride sweat sensor: The critical role of the salt bridge. Anal. Chem. 2016, 88, 12241-12247. [CrossRef] [PubMed]

11. Choi, D.H.; Thaxton, A.; cheol Jeong, I.; Kim, K.; Sosnay, P.R.; Cutting, G.R.; Searson, P.C. Sweat test for cystic fibrosis: Wearable sweat sensor vs. standard laboratory test. J. Cyst. Fibros. 2018, 17, e35-e38. [CrossRef] [PubMed]

12. Rock, M.J.; Makholm, L.; Eickhoff, J. A new method of sweat testing: The CF quantum (R) sweat test. J. Cyst. Fibros. 2014, 13, 520-527. [CrossRef]

13. Kubáň, P.; Greguš, M.; Pokojova, E.; Skrickova, J.; Foret, F. Double opposite end injection capillary electrophoresis withcontactless conductometric detection for simultaneous determinationof chloride, sodium and potassium in cystic fibrosis diagnosis. $J$. Chromatogr. A 2014, 1358, 293-298. [CrossRef]

14. ̌urč, P.; Foret, F.; Pokojová, E.; Homola, L.; Skřričková, J.; Herout, V.; Dastych, M.; Vinohradská, H.; Kubáň, P. New approach for cystic fibrosis diagnosis based on chloride/potassium ratio analyzed in non-invasively obtained skin-wipe sweat samples by capillary electrophoresis with contactless conductometric detection. Anal. Bioanal. Chem. 2017, 409, 3507-3514. [CrossRef] [PubMed]

15. Durč, P.; Foret, F.; Homola, L.; Malá, M.; Pokojová, E.; Vinohradská, H.; Dastych, M.; Krausová, D.; Nagy, D.; Bede, O.; et al. Skin wipe test: A simple, inexpensive, and fast approach in the diagnosis of cystic fibrosis. Pediatr. Pulmonol. 2020, 55, 1653-1660. [CrossRef] [PubMed]

16. European Union. Directive (EU) 2019/904 of the European Parliament and of the Council of 5 June 2019 on the Reduction of the Impact of Certain Plastic Products on the Environment. Available online: https://eur-lex.europa.eu/eli/dir/2019/904/oj (accessed on 29 November 2021).

17. Dubot, P.; Liang, J.; Dubs, J.; Missiak, Y.; Sarazin, C.; Couderc, F.; Causse, E. Sweat chloride quantification using capillary electrophoresis. Pract. Lab. Med. 2009, 13, e00114. [CrossRef] [PubMed]

18. Castellani, C.; Duff, A.J.; Bell, S.C.; Heijerman, H.G.; Munck, A.; Ratjen, F.; Sermet-Gaudelus, I.; Southern, K.W.; Barben, J.; Flume, P.A.; et al. ECFS best practice guidelines: The 2018 revision. J. Cyst. Fibros. 2018, 17, 153-178. [CrossRef] [PubMed]

19. Zemann, A.J. Sub-minute separations of organic and inorganic anions with co-electroosmotic capillary electrophoresis. J. Chromatogr. A 1997, 787, 243-251. [CrossRef] 
20. Rainelli, A.; Hauser, P.C. Fast electrophoresis in conventional capillaries by employing a rapid injection device and contactless conductivity detection. Anal. Bioanal. Chem. 2005, 382, 789-794. [CrossRef]

21. GreyScan. ETD-100 Portable Explosive Detector. Available online: https://greyscandetection.com/products/details/18/etd-100portable-explosive-detector.html (accessed on 29 November 2021). 